\title{
MECANISMOS ECONÓMICOS EN LA LEY DE AGUAS ESPAÑOLA. ¿INSTRUMENTOS PARA LA SOSTENIBILIDAD?*
}

\author{
José Antonio Sotelo Navalpotro ${ }^{1}$ \\ María Sotelo Pérez ${ }^{2}$ \\ Ignacio Sotelo Pérez ${ }^{3}$ \\ ${ }^{1}$ Instituto Universitario de Ciencias Ambientales (IUCA/UCM). Grupo de Investigación: Desarrollo y Gestión Ambiental del \\ Territorio. Universidad Complutense de Madrid \\ jasotelo@ucm.es \\ ${ }^{2}$ Universidad Rey Juan Carlos (URJC). Grupo de Investigación: Desarrollo y Gestión Ambiental del Territorio \\ maria.sotelo.perez@urjc.es \\ ${ }^{3}$ Instituto Universitario de Ciencias Ambientales (IUCA/UCM). Grupo de Investigación: Desarrollo y Gestión Ambiental del \\ Territorio. Universidad Complutense de Madrid. Contratado FPU \\ ignaciosoteloperez@ucm.es
}

\section{RESUMEN}

La denominada "nueva cultura del agua" en nuestro país debe basarse en una política hidráulica renovada, adaptada a la nueva problemática territorial, económica y social de España. El presente estudio tiene como finalidad, diferenciar, definir y analizar los distintos mecanismos económicos que configuran la Ley de Aguas española 29/1985 y sus posteriores modificaciones (Ley de Aguas 46/1999 y Texto Refundido de la Ley de Aguas, Real Decreto 1/2001), así como describir la repercusión, directa o indirecta, que estos tienen con respecto a la protección, preservación, conservación y restauración de los recursos hídricos de nuestro país; sin olvidarnos que en España, desde hace más de más de doscientos años se han aplicado políticas calificables de derrochadoras, casi siempre subvencionadas, en un recurso que, a pesar de todo, es escaso.

Palabras clave: Desarrollo, Instrumentos económicos, Ley de Aguas, Medioambiente, Canon.

Fecha de recepción: mayo 2016.

Fecha de aceptación: abril 2017.

* La presente investigación se enmarca en el Proyecto de Investigación MINECO (2014). CTM201341750-P. 


\section{ABSTRACT}

The so-called "new water culture" in our country must be based on a renewed water policy, adapted to the new territorial, economic and social problems of Spain. The purpose of this study is to differentiate, define and analyze the different economic mechanisms that make up the Spanish Water Law 29/1985 and its subsequent amendments (Law of Water 46/1999 and Revised Text of the Water Law, Royal Legislative Decree 1/2001), as well as describe the impact, direct or indirect, that these have with respect to the protection, preservation, conservation and restoration of the water resources of our country; without forgetting that in Spain, for more than two hundred years have been applied policies qualifiable wasteful, Almost always subsidized, in a resource that, despite everything, is scarce.

Keywords: Development, Economic instruments, Water Law, Environment, Canon.

\section{PRIMERA APROXIMACIÓN}

La preocupación por los problemas derivados de la interacción de las relaciones entre naturaleza y sociedad, y en general por las cuestiones ambientales, cobra relativa importancia a la hora de tratar de la gestión del agua en España durante parte del siglo XIX, del siglo XX y en las primeras décadas del XXI, fenómeno éste que ha estado regido en nuestro país, por la continua intervención estatal, la cual se fundamentaba, principalmente, en políticas de oferta basadas en la construcción de grandes e importantes obras hidráulicas, cuya finalidad no era otra que incrementar la oferta de agua disponible y generación de energía hidroeléctrica. De este modo, España asentaba las bases de una importante política de desarrollo económico, entorno a un recurso escaso como es el agua. Por ello, para hacer frente a estos problemas de escasez, tradicionalmente, las administraciones públicas competentes han puesto en marcha medidas que permitieran resolver dichas problemáticas. Éstas medidas se han caracterizado, como hemos definido anteriormente, por ser políticas de oferta, mediante la construcción de obras hidráulicas muy costosas (cabe señalar que eran obras fundamentales e imprescindibles), no sólo de almacenamiento sino que también de distribución y transporte del recurso hídrico. Las políticas de demanda que esencialmente se han instrumentalizando en España son, la tarifación, la modernización de infraestructuras, la reasignación de los derechos de uso del agua por parte de la Administración y la instauración de mercados de agua. Si de forma amplia y genérica, consideramos el medio ambiente como un sistema integral que engloba de forma interrelacionada e interconectada elementos abióticos, bióticos y sociales, incluyendo en estos últimos factores económicos, culturales e incluso estéticos, entonces la comprensión de su problemática exige entender con igual énfasis la dinámica de los procesos sociales y de los ecológicos y, en suma, las complejas relaciones entre sociedad y naturaleza (García Ballesteros, A. 2000). Tarea de innegable complejidad, que constituye, uno de los más difíciles y ambiciosos desafíos a los que debe enfrentarse la humanidad, exigiendo la colaboración de múltiples disciplinas científicas, que se ven obligadas a una revisión teórica, metodológica y técnica, que permita, sin excluir las especializaciones, una visión sistemática de la totalidad y, en suma, una perspectiva "transdisciplinar". 
Debemos partir de la idea según la cual, en España, la eficacia recaudatoria de las exacciones estipuladas en la Ley de Aguas 29/1985 es muy baja, como consecuencia directa del régimen económico-financiero y por la escasa efectividad del sistema de cobro de las exacciones. «Todo ello impide, en primer lugar, la recuperación de los recursos financieros necesarios para una adecuada vigilancia, control, administración, mantenimiento de las infraestructuras hidráulicas y protección del dominio público hidráulico. En segundo lugar, muestra la escasa internalización de los costes generados en el proceso por parte de los usuarios» (Libro Blanco del Agua, 1998). De igual modo, el reparto de dichas recaudaciones en el territorio español es diverso, complejo y poco equitativo en los momentos actuales, ya que son las propias Comunidades Autónomas las que marcan los precios del agua teniendo en cuenta las condiciones bioclimáticas y territoriales de la propia cuenca o cuencas hidrográficas dentro de las que se enmarca; este es un hecho que cobra gran importancia en el punto y hora en el que en algunas zonas de España se desperdicia el agua o no se le da el valor que este bien requiere, mientras que en otras Comunidades el precio excede a la media nacional como consecuencia directa de la falta de agua.

Y es así como nos encontramos con la primera de 1866. Si bien, ésta no entró en vigor por las condiciones política y sociales de la época, sirvió de base la para la posterior Ley de Aguas de 1879, la cual recogía en su texto todas y cada una de las aguas de dominio público existente en España, ya fueran ríos, lagos, corrientes naturales,... aunque, no se incluyeron las aguas subterráneas (cuestión de suma importancia que si fue incluida en la Ley de Aguas de 1985). De este modo, se estableció el nuevo régimen jurídico del dominio público hidráulico, entorno a las bases constitucionales de la Constitución de 1978, en la cual se recoge la división de competencias entre el propio Estado y la delegación de ciertas competencias a las Comunidades Autónomas, estableciendo de este modo, un nuevo sistema normativo de las distintas Administraciones Públicas competentes.

Con todo ello, debemos tener en cuenta que, a la hora de tratar la gestión compleja del recurso hídrico en España, existe una gran variedad de legislaciones que regulan y gestionan el abastecimiento del agua. Para ello podemos hacer una distinción entre el Marco Legal Internacional, el Marco Legal Nacional de España, mediante las Confederaciones Hidrográficas y los Organismos de Cuencas, si bien, lo que nos interesa en el presente estudio es, únicamente, el Marco Legal Nacional de España, en el que se encuadra la propia Ley de Aguas española del año 1985, la cual se ha ido modificando progresivamente en los últimos años, presentando gran interés los distintos instrumentos económicos vinculados, fundamentalmente, a la protección del Medio Ambiente. Gracias a esta Ley de Aguas y a sus correspondientes modificaciones, se ha permitido constatar tanto la existencia de diversos problemas prácticos en la gestión del agua a nivel nacional, como la ausencia en ella de instrumentos eficaces para afrontar las nuevas demandas en relación con dicho recurso, tanto en cantidad, dado que su consumo se incrementa exponencialmente, como en calidad, y, más concretamente, en términos de protección medioambiental.

La Ley de Aguas (art. 38. Ley 29/1985) tiene como finalidad conseguir el buen estado ecológico del dominio público hidráulico, conseguir la satisfacción de las demandas de agua y equilibrar y armonizar el desarrollo regional y sectorial y todo ello, incrementando las disponibilidades del recurso, protegiendo su calidad, economizando su empleo, racionalizando sus usos en armonía con el medio ambiente y los demás recursos natura- 
les. A su vez, debemos tener en cuenta que, con independencia de la mejor reasignación de los recursos disponibles, a través de mecanismos de planificación, permitan, de un lado, incrementar la producción de agua mediante la utilización de nuevas tecnologías, otorgando rango legal al régimen jurídico de los procedimientos de desalación o de reutilización, de otro, potenciar la eficiencia en el empleo del agua para lo que es necesario la requerida flexibilización del actual régimen concesional a través de la introducción del nuevo contrato de cesión de derechos al uso del agua, que permitirá optimizar socialmente los usos de un recurso tan escaso, y, por último, introducir políticas de ahorro de dicho recurso, bien estableciendo la obligación general de medir los consumos de agua mediante sistemas homologados de control o por medio de la fijación administrativa de consumos de referencia para regadíos (exposición de motivos de la Ley de Aguas 29/1985). Es por esto por lo que, se impone realizar nuevas modificaciones y reformas en la actual Ley de Aguas, haciendo especial hincapié en los instrumentos económicos, fundamentados no sólo en la homogeneización de la tarificación del recurso hídrico, sino también en pro de “prevenir antes que curar", en materia medioambiental. Tal y como señaló el Consejo de Estado ya en 1962 sobre la Ley de Aguas de 1879, la de 1985 deberán subsistir, si bien con los retoques y modificaciones necesarios para actualizar su técnica y solventar los problemas más acuciantes que la experiencia administrativa, ha venido acusando", pero sin alterar sus principios.

\section{JUSTIFICACIÓN}

En nuestro estudio marcamos como finalidad principal, diferenciar, definir y analizar los distintos mecanismos económicos que configuran la Ley de Aguas española, amén de describir la repercusión, directa o indirecta, que éstos tienen con respecto a la protección, preservación, conservación y restauración de los recursos hídricos de nuestro país. A lo largo de nuestra disertación científica puede observarse una evolución ciertamente compleja, de los Instrumentos Económicos recogidos en la primera Ley de Aguas 29/1985, de 2 de agosto y la progresiva afección a esta Ley que se no se ha derogado materialmente, pero cuyas líneas fundamentales van perdiendo consistencia dada la modificación continua que se va a describir, superponiéndose los textos de las distintas leyes que modifican o derogan a la propia Ley de Aguas de 1985. Todo ello, con el fin último de establecer una visión general de la relación existente entre éstos y su capacidad de internalizar costes externos generados por un mal uso del recurso hídrico, afectando de manera negativa al medio ambiente en general y al agua como bien escaso, en particular.

En el inicial texto de la Ley de Aguas 29/1985 existe un predominio de los instrumentos fiscales y parafiscales, pero cada vez más la tendencia apunta a que éstos se apliquen conjuntamente con otros mecanismos de mercado, (sobre todo, a partir del Texto Refundido de la Ley de Aguas 1/2001) y, sistemas de autorregulación, como son los Acuerdos Voluntarios, principalmente, en la Ley 62/2003, en la Ley 11/2005, en la Ley 11/2012, y en la Ley 15/2012. Con todo ello, decir que existen cuatro categorías diferentes de instrumentos económicos, entre los que podemos clasificar a aquellos que conforman la Ley de Aguas española (Jiménez Herrero, J.L., 1998): los que afectan al precio de los productos; todo el conjunto de tasas e impuestos ambientales, subvenciones, sistemas de depósito 
y retorno; los que limitan los niveles de contaminación o de degradación ambiental, que incluye buena parte de los mecanismos de mercado, como son los permisos de emisión, los mercados de "residuos" y los referentes al recurso hídrico (mercados y "bancos de agua"); los Acuerdos Voluntarios, que pertenecen también a este nuevo sistema de autorregulación de las empresas, donde se pueden incluir diferentes mecanismos reguladores con capacidad de dinamizar las fuerzas del mercado, como las "eco-auditorías", la "eco-gestión", las "ecoetiquetas". Por último, los instrumentos financieros que ofrecen otras ventajas financieras-fiscales, que de algún modo también incitan al agente contaminador a que se comprometa mucho más en la mejora de la calidad del medio ambiente.

Por otra parte, señalar que los mecanismos económicos, en general, tienen ventajas sobre el clásico sistema de regulación directa (normas y regulación administrativas), por su mayor eficiencia para internalizar los costes externos ambientales de cada situación particular de contaminación ambiental. Según la Teoría Económica, determinados instrumentos económicos y, entre ellos, los diferentes gravámenes "impuestos a la contaminación" son un procedimiento adecuado para corregir ciertos fallos de mercado (ausencia de un precio de mercado para los bienes ambientales) e internalizar la externalidad negativa de la contaminación, compensando el daño externo producido (acercamiento de los precios al verdadero coste social de los recursos empleados). Este punto óptimo de contaminación se logra teóricamnte cuando los Beneficios Marginales se igualan a los correspondientes Costes Marginales. Ante las dificultades de evaluación de los costes del daño ambiental, el procedimiento económico tradicional se centra en fijar un gravamen, tasa, canon directo y proporcional a la cantidad de contaminación emitida, tratando de alcanzar el punto óptimo cuando aquél iguala el Coste Marginal del control de la contaminación producida por el agente contaminante. Así pues, la teoría económica sugiere, en condiciones de competencia perfecta, que el juego del mercado facilita las decisiones de protección ambiental para encontrar soluciones de costes mínimos. Con la utilización de mecanismos basados en el mercado, las administraciones proporcionan incentivos de ajuste de precios en lugar de exigencias de control. Por otra parte, el uso de instrumentos económicos no coacciona directamente al contaminador. Y supone incentivos permanentes para propiciar el cambio tecnológico, la producción y el consumo ecológico (Jiménez Herrero, J.L., 1998).

Teniendo en cuenta lo anteriormente expuesto, en España, en el caso concreto de la Ley de Aguas de 29/1985, la escasa aplicación de instrumentos económicos y fiscales se debe, entre otras cosas, a determinadas rigideces estructurales del sistema fiscal español que no permiten incorporar con agilidad ciertas figuras tributarias avanzadas con una finalidad ambiental y un carácter extrafiscal. En general, el uso de mecanismos económicos y fiscales, se ha orientado fundamentalmente al sector de aguas utilizando figuras específicas normalmente denominadas "canones"; de igual modo, con carácter general, podemos decir que de acuerdo con las competencias autonómicas en materia del medio ambiente, se van incorporando sucesivas figuras establecidas a nivel estatal, como es el caso de la Ley de Aguas de 29/1985 en el que existen diversos cánones a nivel estatal, los Canones de Vertidos o el Canon por obras de regulación de aguas superficiales o subterráneas y el Canon de utilización del dominio público hidráulico. Precisamente dentro de este sector, existen múltiples cánones establecidos por las Comunidades Autónomas, de un carácter com- 
plementario con diversa denominación (abastecimiento, saneamiento, vertido, regulación hidráulica, depuración de aguas), tales como los establecidos por primera vez en Cataluña (1981), País Vasco, Galicia (1993), Asturias (1994), Baleares (1991), Canarias (1987), ...

\section{REPERCUSIONES EN LA LEY DE AGUAS DE LOS INSTRUMENTOS ECONÓMICOS EN EL ÁMBITO DEL MEDIO AMBIENTE}

Para entender la repercusión que ha tenido y tiene la Ley de Aguas española, hemos tratado los diferentes instrumentos con los que la Ley ha contado para regular los distintos usos del agua; por ello, desglosamos todos los instrumentos económicos de dicha Ley, atendiendo a los conceptos tributarios básicos y, posteriormente, comparando la evolución de estos en la Ley de Aguas 29/1985, la Ley de Aguas 46/1999 y el Texto Refundido de la Ley de Aguas, Real Decreto 1/2001.

Respecto de la Ley de Aguas de 1985 introdujo tres grandes novedades imbricadas con su objeto: "La regulación del dominio público hidráulico, del uso del agua, y, del ejercicio de las competencias atribuidas al Estado en las materias relacionadas con dicho dominio en el marco de las competencias delimitadas en el artículo 149 de la Constitución” (Art. 1 Ley de Aguas). En el primer aspecto, la gran novedad fue la consideración como dominio público de todas las aguas que forman parte del ciclo hidrológico, incluyendo las subterráneas renovables. En el segundo, la regulación de la planificación hidrológica como instrumento clave para la gestión de los recursos. En el tercero, la adaptación de las competencias estatales a los enunciados constitucionales y estatutarios, nada fáciles de interpretar (Embid Irujo, A. 2016).

Y, es que, la Ley de Aguas de 1985, y el Texto Refundido de la Ley de Aguas del 2001, han intentado resolver los problemas históricos surgidos con la política de la oferta generada por los ideales regeneracionistas de Costa, adaptándose a una nueva cultura del agua mediante la modernización de su gestión, si bien, el desapoderamiento del Estado a manos de las Comunidades Autónomas, en no pocos casos, la está frenando; todo ello unido a la gran cantidad de dinero que se está dedicando a la modernización de infraestructuras cuyos beneficios no son tangibles a corto plazo, y, por la denominada cultura del usuario, muy alejada del desarrollo sostenible, lo que lleva a afirmar al profesor Embid que "el signo distintivo del Derecho español de aguas en la actualidad es su indefinición" (Embid Irujo, A. 2002). Todo esto unido a la insostenibilidad que supone el contar con una política hidráulica en la que prácticamente no existe la idea de generalidad, de unión, de unidad. Vivimos una etapa marcada por los particularismos, y por la fragmentación generada por unos intereses territoriales que han segmentado, de facto, la gestión del agua, con la única excepción, a nuestro entender, de la susodicha Ley de Aguas. Igualmente, destacar la ruptura del principio de gestión integrada y de unidad de cuenca, la quiebra del principio de cooperación autonómica, y la incapacidad del Estado para ejercer su autoridad en un campo en el que es imprescindible. Como afirman varios autores, Francisco Cabezas et ali, en España "cada región fija en sus propios intereses sin importar nada la visión nacional, la política a seguir" (Cabezas Calvo-Rubio, F. et alii, 2010).

Por todo ello, analizar los mecanismos económicos principales nos lleva a aproximarnos al Título VI del régimen económico-financiero de la utilización del dominio público hidráulico y, de forma concreta al "canon de ocupación” (art. 104 de la Ley de aguas de 29/1985), modificado por el artículo 40 de la Ley 46/1999 del 13 de diciembre, donde se le denomina 
“canon de utilización de los bienes del dominio público hidráulico" y, posteriormente, regulado por el artículo 112 del Texto refundido de la Ley de aguas, Real Decreto Legislativo 1/2001 (cuadro 1).

1. La ocupación o utilización que requiera autorización o concesión de los bienes del dominio público hidráulico, a que se refieren los apartados b) y c) del artículo 2 de esta Ley, se gravará con un canon destinado a la protección y mejora de dicho dominio, cuya aplicación se hará pública por el Organismo de cuenca. Los concesionarios de aguas estarán exentos del pago del canon por la ocupación o utilización de los terrenos del dominio público necesarios para llevar a cabo la concesión.

2. La base imponible de esta exacción será el valor del bien utilizado, teniendo en cuenta el rendimiento que reporte. El tipo de gravamen anual será el 4 por 100 sobre el valor de la base imponible.

3. Este canon será gestionado y recaudado, en nombre del Estado, por los Organismos de cuenca, quienes informarán al Ministerio de Economía y Hacienda periódicamente en la forma en que el mismo determine.

La Ley de Aguas encomienda el régimen económico referente a la disponibilidad del agua a las tasas denominadas canon de regulación y tarifas de utilización del agua. Así, pues, nos encontramos ante un canon, que regula la ocupación o uso del dominio público hidráulico. Puesto que en el texto se expone como objetivo la protección y mejora de dicho dominio, claramente, estamos ante un instrumento económico, que podríamos denominar "extrafiscal". En la Ley se recoge la importancia de la ocupación o utilización autorizada del dominio público hidráulico, de los cauces de corrientes naturales y los lechos de los lagos, lagunas y los embalses superficiales en cauces públicos. De hecho, tal y como se expone en el propio artículo 104 de dicha Ley de Aguas; La base imponible de esta exacción será el valor del bien utilizado, teniendo en cuenta el rendimiento que reporte. Los sujetos pasivos serán todos aquellos titulares de las concesiones o de las autorizaciones de ocupación o utilización, mientras que el tipo de gravamen anual será el $4 \%$ sobre el valor de la base imponible, con una cuota tributaria que en nuestro caso, el resultado de aplicar a la base imponible el tipo de gravamen anteriormente expuesto. Debemos tener en cuenta que dicha cuota tributaria será determinada por cada Organismo de Cuenca, atendiendo a diversas condiciones intrínsecas del territorio en el que se aplique dicho "canon". Por su parte, el criterio de imputación temporal de dicho canon estará determinando por el momento exacto en que se proceda a la concesión del uso del dominio público hidráulico, atendiendo a las condiciones concretas expuestas en dichas autorizaciones.

Por otra parte, podemos destacar por su importancia del Título VI del régimen económicofinanciero de la utilización del dominio público hidráulico, el "canon de vertidos" (art. 105 de la Ley de aguas de 29/1985), fue modificado por el artículo 41 de la Ley 46/1999 del 13 de diciembre, donde se le denomina "canon de control de vertidos" y, posteriormente, se ha 
visto regulado por el artículo 113 del Texto refundido de la Ley de aguas, Real Decreto Legislativo 1/2001. De igual modo, debemos tener presente el Real Decreto 849/1986 (cuadro 2).

1. Los vertidos autorizados, conforme a lo dispuesto en los artículos 92 y siguientes de esta Ley, se gravarán con un canon destinado a la protección y mejora del medio receptor de cada cuenca hidrográfica.

2. El importe de esta exacción será el resultado de multiplicar la carga contaminante del vertido, expresada en unidades de contaminación, por el valor que se asigne a la unidad. Se entiende por unidad de contaminación un patrón convencional de medida, que se fijará reglamentariamente, referido a la carga contaminante producida por el vertido-tipo de aguas domésticas, correspondiente a 1.000 habitantes y al período de un año. Asimismo, por vía reglamentaría se establecerán los baremos de equivalencia para los vertidos de aguas residuales de otra naturaleza. El valor de la unidad de contaminación, que podrá ser distinto para los distintos ríos y tramos de río, se determinará y revisará, en su caso, de acuerdo con las previsiones de los Planes Hidrológicos respecto a la calidad de las aguas continentales, de modo que se cubra la financiación de las obras necesarias para el cumplimiento de dichas previsiones.

3. Este canon será percibido por los Organismos de cuenca y será destinado a las actuaciones de protección de la calidad de las aguas que hayan sido previstas en los Planes Hidrológicos de cuenca, a cuyo efecto se pondrá a disposición de los organismos competentes.

4. Cuando el sujeto pasivo del canon de vertido viniera obligado a soportar otras cargas económicas, ya establecidas o que puedan serlo por las Comunidades Autónomas o por las Corporaciones Locales, en el ejercicio de sus competencias, para financiar planes o programas públicos de depuración de aguas residuales, el Consejo de Agua determinará anualmente las deducciones que deban realizarse en el importe del canon del vertido.

Del cuadro anterior se deduce que nos encontramos ante un Canon, que regula los vertidos autorizados, exclusivamente, realizados directamente por el uso o empleo del dominio público hidráulico. El hecho que da origen a la obligación tributaria son los vertidos autorizados, es decir, los que se realicen directa o indirectamente en los cauces, cualquiera que sea la naturaleza de éstos, así como los que se lleven a cabo en el subsuelo o sobre el terreno, balsas o excavaciones, mediante evacuación, inyección o depósito (atendiendo al art. 92 Ley 29/1985). La carga contaminante del vertido expresada en unidades de contaminación, es decir, el volumen total de los vertidos autorizados, junto con los sujetos pasivos serán todos aquellos obligado

2 Real Decreto 849/1986, de 11 de abril, por el que se aprueba el Reglamento del Dominio Público Hidráulico que desarrolla los títulos preliminar, I, IV, V, VI, VII y VIII del texto refundido de la Ley de Aguas, aprobado por el Real Decreto Legislativo 1/2001, de 20 de julio. 
a soportar otras cargas económicas, producidas por los vertidos autorizados en el dominio público hidráulico. Por su parte, el tipo de gravamen está determinado por el precio de control de los vertidos autorizados que se determinará y revisará, en su caso, de acuerdo con las previsiones de los Planes Hidrológicos respecto a la calidad de las aguas continentales. La cuota tributaria, por su parte, se obtendrán de multiplicar la base imponible (ya que no hay reducciones), por el tipo de gravamen, es decir, de multiplicar el volumen de vertido autorizado por el precio unitario de control de vertido. Tdo ello sin olvidar que en el artículo 105 de la Ley de Aguas 29/1985 no se estipula el momento exacto del periodo de devengo.

Igualmente, hay que destacar del Título VI del régimen económico-financiero de la utilización del dominio público hidráulico, el "canon de regulación y la tarificación de uso de agua" (art. 106 de la Ley de aguas de 29/1985), fue modificado por el artículo 42 de la Ley 46/1999 del 13 de diciembre y, posteriormente, se ha visto regulado por el artículo 113 del Texto refundido de la Ley de aguas, Real Decreto Legislativo 1/2001 (cuadro 3).

1. Los beneficiados por las obras de regulación de aguas superficiales o subterráneas realizadas total o parcialmente, a cargo del Estado, satisfarán un canon destinado a compensar la aportación del Estado y atender a los gastos de explotación y conservación de tales obras.

2. Los beneficios por otras obras hidráulicas específicas realizadas íntegramente a cargo del Estado, incluidas las de corrección del deterioro del dominio público hidráulico, derivado de su utilización, satisfarán por la disponibilidad o uso del agua una exacción destinada a compensar los costes de inversión y atender a los gastos de explotación y conservación de tales obras.

3. La cuantía de cada una de las exacciones se fijará para cada ejercicio presupuestario, sumando las siguientes cantidades:

a) El total previsto de gastos de funcionamiento y conservación de las obras realizadas.

b) Los gastos de administración del organismo gestor imputables a dichas obras.

c) El 4 por 100 del valor de las inversiones realizadas por el Estado, debidamente actualizado, teniendo en cuenta la amortización técnica de las obras e instalaciones y la depreciación de la moneda, en la forma que reglamentariamente se determine.

4. La distribución individual de dicho importe global, entre todos los beneficiados por las obras, se realizará con arreglo a criterios de racionalización del uso del agua, equidad en el reparto de las obligaciones y autofinanciación del servicio, en la forma que reglamentariamente se determine.

5. Estas exacciones serán gestionadas y recaudadas, en nombre del Estado, por los Organismos de cuenca, quienes informarán al Ministerio de Economía y Hacienda periódicamente en la forma en que el mismo determine. 
De la información anterior se colige que nos encontramos ante dos tributos, que son el "canon de regulación" y, por otro lado, lo que podemos calificar de "contribuciones especiales", que es la "tarificación de uso de agua". El uso o disfrute, directo o indirecto, de obras de regulación de aguas superficiales o subterráneas realizadas total o parcialmente, a cargo del Estado y, el uso y disfrute de otras obras hidráulicas específicas realizadas íntegramente a cargo del Estado. La cuantía prevista de los gastos de funcionamiento, conservación y administración por parte del organizador, de las obras realizadas; teniendo en cuenta que todos aquellos que se beneficien directa o indirectamente, de obras de regulación de aguas superficiales o subterráneas realizadas total o parcialmente, a cargo del Estado y, el uso y disfrute de otras obras hidráulicas específicas realizadas íntegramente a cargo del Estado. Por su parte, el tipo de gravamen son del 4\% del valor de las inversiones realizadas por el Estado, debidamente actualizado, teniendo en cuenta la amortización técnica de las obras e instalaciones y la depreciación de la moneda, en la forma que reglamentariamente se determine. La cuota tributaria es el resultado de aplicar el tipo de gravamen a la base imponible, es decir, aplicar el tipo impositivo a la cuantía de los gastos de funcionamiento, conservación y administración por parte del organizador, de las obras realizadas. El criterio de imputación temporal de dicho canon estará determinando por el momento exacto en que se produzca el uso o disfrute de dichas obras hidráulicas. Todo esto se vio ampliado con las modificaciones realizadas posteriormente.

\section{III.1. Modificaciones de los Instrumentos Económicos de la Ley de Aguas 46/1999}

La Ley de Aguas 46/1999, prácticamente no altera la legislación existente de la Ley de Aguas 29/1985, aunque si realiza ciertas modificaciones, con el afán de perfeccionarla y renovarla para, de ese modo, tal y como recoge la propia legislación, «dar respuesta a sus insuficiencias, a los nuevos retos que exige la gestión del agua a las puertas del siglo XXI, en concordancia con nuestra plena integración en la Unión Europea y la necesidad de otorgar la máxima protección a dicho recurso natural como bien medioambiental de primer orden». A estos efectos, la Ley 46/1999 procede a la modificación y reestructuración de los distintos instrumentos económicos e incorporan otros nuevos, tal y como vamos a analizar, con la intención de introducir mejoras técnicas, al mismo tiempo que regula algunas materias que no figuraban incluidas en ella, tales como la desalación, la cesión de derechos de uso del agua o las obras públicas. En ella destaca por su importancia el Título VI del régimen económico-financiero de la utilización del dominio público hidráulico, y, de forma concreta, el "canon de utilización de los bienes del dominio público hidráulico" (art. 40 de la Ley de aguas de 46/1999), por el cual se modifica el artículo 104 de la Ley 29/1985, donde se le denomina "canon de ocupación" y, posteriormente, se ha visto regulado por el artículo 112 del Texto refundido de la Ley de aguas, Real Decreto Legislativo 1/2001. Cabe destacar que se modifica la redacción del artículo 104 de la Ley 29/1985 y se incorporan los apartados 2 y 3 (cuadro 4).

La información anterior nos muestra que, al igual que en la originaria Ley de Aguas 29/1985, nos encontramos ante un Canon, que regula la ocupación o uso del dominio público hidráulico. Puesto que en el texto se expone como objetivo la protección y mejora de dicho dominio, claramente nos encontramos ante un instrumento económico que podríamos deno- 
1. La ocupación, utilización o aprovechamiento de los bienes del dominio público hidráulico incluidos en los apartados b) y c) del artículo 2 de la presente Ley, que requieran concesión o autorización administrativa, devengarán a favor del Organismo de cuenca competente una tasa denominada canon de utilización de bienes del dominio público hidráulico, destinada a la protección y mejora de dicho dominio. Los concesionarios de aguas estarán exentos del pago del canon por la ocupación o utilización de los terrenos de dominio público necesarios para llevar a cabo la concesión.

2. El devengo de la tasa se producirá con el otorgamiento inicial y el mantenimiento anual de la concesión o autorización y será exigible en la cuantía que corresponda y en los plazos que se señalen en las condiciones de dicha concesión o autorización.

3. Serán sujetos pasivos del canon los concesionarios o personas autorizadas o, en su caso, quienes se subroguen en lugar de aquéllos.

4. La base imponible de la exacción se determinará por el Organismo de cuenca según los siguientes supuestos: a) En el caso de ocupación de terrenos del domino público hidráulico, por el valor del terreno ocupado tomando como referencia el valor de mercado de los terrenos contiguos. b) En el caso de utilización del dominio público hidráulico, por el valor de dicha utilización o del beneficio obtenido con la misma. c) En el caso de aprovechamiento de bienes del dominio público hidráulico, por el valor de los materiales consumidos o la utilidad que reporte dicho aprovechamiento.

5. El tipo de gravamen anual será del 5 por 100 en los supuestos previstos en las letras a) y b) del apartado anterior, y del 100 por 100 en el supuesto de la letra c), que se aplicarán sobre el valor de la base imponible resultante en cada caso.

6. En el supuesto de cuencas intercomunitarias este canon será recaudado por el Organismo de cuenca o bien por la Administración tributaria del Estado, en virtud de convenio con aquél. En este segundo caso la Agencia Estatal de Administración Tributaria recibirá del Organismo de cuenca los datos y censos pertinentes que faciliten su gestión, e informará periódicamente a éste en la forma que se determine por vía reglamentaria. El canon recaudado será puesto a disposición del Organismo de cuenca correspondiente.

minar extrafiscal. No se ve modificado, el hecho imponible continúa siendo la ocupación o utilización autorizada del dominio público hidráulico, únicamente, de los cauces de corrientes naturales y los lechos de los lagos, lagunas y los embalses superficiales en cauces públicos; se produce una modificación en la cual se estipula que la base imponible dependerá de tres factores clave: el primero de ellos será el valor de mercado del terreno ocupado (a precios de mercado), tomando como referencia lo terrenos limítrofes en el caso de ocupación de terrenos de domino público hidráulico; el segundo viene determinado por el valor de ocupación o uso del terreno; y, por último, el valor de los bienes vs. servicios del aprovecha- 
miento de terrenos de dominio público hidráulico. En esta modificación de la Ley de Aguas se estipula quien será sujeto pasivo, definiendo a este como los concesionarios o personas autorizadas o, en su caso, quienes se subroguen en lugar de aquéllos (y es que, en el texto originario no se definen a los sujetos pasivos) El tipo de gravamen anual se incrementa de un $4 \%$ al 5\% sobre el valor de la base imponible, sólo en los casos de ocupación o utilización de terrenos de dominio público hidráulico; ascendiendo dicha cantidad al 100\% en caso de aprovechamiento de dominio público hidráulico. Respecto de la cuota tributaria decir que es aquella cantidad que representa el gravamen, en nuestro caso, el resultado de aplicar a la base imponible el tipo de gravamen anteriormente expuesto, atendiendo a las condiciones descritas en el artículo 40. Debemos tener en cuenta que dicha cuota tributaria será determinada por cada Organismo de Cuenca, atendiendo a diversas condiciones intrínsecas del territorio en el que se aplique dicho "canon". Añadir que tal y como se describe en el apartado 3, el devengo se producirá con el otorgamiento inicial y el mantenimiento anual de la concesión o autorización y será exigible en la cuantía que corresponda y en los plazos que se señalen en las condiciones de dicha concesión o autorización.

Llegados a este punto, destacar por su importancia del Título VI del régimen económicofinanciero de la utilización del dominio público hidráulico, el "canon de control de vertidos" (art. 41 de la Ley de aguas de 46/1999), fue modifica el artículo 105 de la Ley 29/1985 denominado "canon de vertidos" y, posteriormente, regulado por el artículo 113 del Texto refundido de la Ley de aguas, Real Decreto Legislativo 1/2001. De igual modo, debemos tener presente el Real Decreto 849/198. Se modifica la redacción del artículo 105 de la Ley 29/1985 y se incorporan los apartados 2, 4 y 7 (cuadro 5).

$\mathrm{Al}$ analizar la información anterior podemos destacar que nos encontramos ante un Canon, que regula los vertidos autorizados, exclusivamente, realizados directamente por el uso o empleo del dominio público hidráulico. A diferencia de la Ley de Aguas 29/1985, en el presente texto se estipula que, el hecho que da origen a la obligación tributaria, serán todos aquellos vertidos (autorizados o no) que se realicen directa o indirectamente en los cauces, cualquiera que sea la naturaleza de éstos, así como los que se lleven a cabo en el subsuelo o sobre el terreno, balsas o excavaciones, mediante evacuación, inyección o depósito (atendiendo al art. 92 Ley 29/1985). En ella se recoge que la carga contaminante del vertido va expresada en unidades de contaminación, es decir, el volumen total de los vertidos autorizados, con un sujeto pasivo que en el texto anterior se estipulaba que eran los obligados a soportar otras cargas económicas, producidas por los vertidos autorizados en el dominio público hidráulico; mientras que en esta modificación de la ley 29/1985, se establece que los sujetos pasivos serán todos aquellos que hayan llevado a cabo el vertido, producidas por los vertidos autorizados en el dominio público hidráulico. El tipo de gravamen está determinado por el precio de control de los vertidos autorizados que se determinará por el precio unitario resultado de multiplicar el precio básico por metro cúbico por un coeficiente de mayoración o minoración, que se establecerá reglamentariamente en función de la naturaleza, características y grado de contaminación del vertido. La cuota tributaria, por su parte, se obtiene de multiplicar la base imponible (ya que no hay reducciones), por el tipo de gravamen, es decir, de multiplicar el volumen de vertido autorizado por el precio unitario de control de vertido; señalando, por último, que el canon de vertidos se devenga los 31 de diciembre de cada año, siendo su periodo impositivo el propio año natural, salvo excepciones detalladas. 
1. Los vertidos al dominio público hidráulico estarán gravados con una tasa destinada al estudio, control, protección y mejora del medio receptor de cada cuenca hidrográfica, que se denominará canon de control de vertidos.

2. Serán sujetos pasivos del canon de control de vertidos, quienes lleven a cabo el vertido.

3. El importe del canon de control de vertidos será el producto del volumen de vertido autorizado por el precio unitario de control de vertido. Este precio unitario se calculará multiplicando el precio básico por metro cúbico por un coeficiente de mayoración o minoración, que se establecerá reglamentariamente en función de la naturaleza, características y grado de contaminación del vertido, así como por la mayor calidad ambiental del medio físico en que se vierte. El precio básico por metro cúbico se fija en 2 pesetas/metro cúbico para el agua residual urbana y en 5 pesetas/ metro cúbico para el agua residual industrial. Estos precios básicos podrán revisarse periódicamente en las Leyes de Presupuestos Generales del Estado. El coeficiente de mayoración del precio básico no podrá ser superior a 4.

4. El canon de control de vertidos se devengará el 31 de diciembre, coincidiendo el período impositivo con un año natural, excepto el ejercicio en que se produzca la autorización del vertido o su cese, en cuyo caso, se calculará el canon proporcionalmente al número de días de vigencia de la autorización en relación con el total del año. Durante el primer trimestre de cada año natural, deberá liquidarse el canon correspondiente al año anterior.

5. En el supuesto de cuencas intercomunitarias este canon será recaudado por el Organismo de cuenca o bien por la Administración tributaria del Estado, en virtud de convenio con aquél. En este segundo caso la Agencia Estatal de Administración Tributaria recibirá del Organismo de cuenca los datos y censos pertinentes que faciliten su gestión, e informará periódicamente a éste en la forma que se determine por vía reglamentaria. El canon recaudado será puesto a disposición del Organismo de cuenca correspondiente.

6. Cuando se compruebe la existencia de un vertido, cuyo responsable carezca de la autorización administrativa a que se refiere el artículo 92, con independencia de la sanción que corresponda, el Organismo de cuenca liquidará el canon de control de vertidos por los ejercicios no prescritos, calculando su importe por procedimientos de estimación indirecta conforme a lo que reglamentariamente se establezca.

7. El canon de control de vertidos será independiente de los cánones o tasas que puedan establecer las Comunidades Autónomas o Corporaciones locales para financiar las obras de saneamiento y depuración.

Por último, hay que destacar del Título VI del régimen económico-financiero de la utilización del dominio público hidráulico, el "canon de regulación y la tarificación de uso de agua" (art. 42 de la Ley de aguas de 46/1999), que modifica el artículo 106 de la Ley 29/1985 y, posteriormente, se ha visto regulado por el artículo 113 del Texto refundido de la Ley de aguas, 
Real Decreto Legislativo 1/2001. Cabe destacar que se modifica la redacción de los apartados 1,2 y 5 del artículo 106 de la Ley 29/1985, y se añaden los apartados 6 y 7 (cuadro 6).

1. Los beneficiados por las obras de regulación de las aguas superficiales o subterráneas, financiadas total o parcialmente con cargo al Estado, satisfarán un canon de regulación destinado a compensar los costes de la inversión que soporte la Administración estatal y atender los gastos de explotación y conservación de tales obras.

2. Los beneficiados por otras obras hidráulicas específicas financiadas total o parcialmente a cargo del Estado, incluidas las de corrección del deterioro del dominio público hidráulico, derivado de su utilización, satisfarán por la disponibilidad o uso del agua una exacción denominada tarifa de utilización del agua, destinada a compensar los costes de inversión que soporte la Administración estatal y a atender a los gastos de explotación y conservación de tales obras.

3. La cuantía de cada una de las exacciones se fijará para cada ejercicio presupuestario, sumando las siguientes cantidades:

a) El total previsto de gastos de funcionamiento y conservación de las obras realizadas.

b) Los gastos de administración del organismo gestor imputables a dichas obras.

c) El 4 por 100 del valor de las inversiones realizadas por el Estado, debidamente actualizado, teniendo en cuenta la amortización técnica de las obras e instalaciones y la depreciación de la moneda, en la forma que reglamentariamente se determine.

4. La distribución individual de dicho importe global, entre todos los beneficiados por las obras, se realizará con arreglo a criterios de racionalización del uso del agua, equidad en el reparto de las obligaciones y autofinanciación del servicio, en la forma que reglamentariamente se determine.

5. En el supuesto de cuencas intercomunitarias las exacciones previstas en este artículo serán gestionadas y recaudadas por el Organismo de cuenca o bien por la Administración tributaria del Estado, en virtud de convenio con aquél. En este segundo caso la Agencia Estatal de la Administración Tributaria recibirá del Organismo de cuenca los datos y censos pertinentes que faciliten su gestión, e informará periódicamente a éste en la forma que se determine por vía reglamentaria. El canon recaudado será puesto a disposición del Organismo de cuenca correspondiente.

6. El organismo liquidador de los cánones y exacciones introducirá un factor corrector del importe a satisfacer, según el beneficiado por la obra hidráulica consuma en cantidades superiores o inferiores a las dotaciones de referencia fijadas en los planes hidrológicos de cuenca o, en su caso, en la normativa que regule la respectiva planificación sectorial, en especial en materia de regadios u otros usos agrarios. Este factor corrector consistirá en un coeficiente a aplicar sobre la liquidación, que no podrá ser superior a 2 ni inferior a 0,5, conforme a las reglas que se determinen reglamentariamente.

7. El Organismo de cuenca aprobará y emitirá las liquidaciones reguladas en este artículo en el ejercicio al que correspondan. 
$\mathrm{Al}$ analizar la información anterior, nos encontramos, de nuevo, ante dos tributos, que son el "canon de regulación" y, por otro lado, lo que podemos calificar de "contribuciones especiales", que es la "tarificación de uso de agua". El uso o disfrute, directo o indirecto, de obras de regulación de aguas superficiales o subterráneas realizadas total o parcialmente, a cargo del Estado y, el uso y disfrute de otras obras hidráulicas específicas realizadas íntegramente a cargo del Estado. La cuantía prevista de los gastos de funcionamiento, conservación y administración por parte del organizador, de las obras realizadas. El sujeto pasivo supone que todos aquellos que se beneficien directa o indirectamente, de obras de regulación de aguas superficiales o subterráneas realizadas total o parcialmente, a cargo del Estado y, el uso y disfrute de otras obras hidráulicas específicas realizadas íntegramente a cargo del Estado, con un tipo de gravamen del $4 \%$ del valor de las inversiones realizadas por el Estado, debidamente actualizado, teniendo en cuenta la amortización técnica de las obras e instalaciones y la depreciación de la moneda, en la forma que reglamentariamente se determine, y, una cuota tributaria que será el resultado de aplicar el tipo de gravamen a la base imponible, es decir, aplicar el tipo impositivo a la cuantía de los gastos de funcionamiento, conservación y administración por parte del organizador, de las obras realizadas, todo ello teniendo en cuenta la normativa de los Planes Hidrográficos de Cuenca. De igual modo, debemos tener en cuenta que el legislador fija los límites máximo y mínimo de este factor, pero las reglas para su cálculo se remiten al reglamento. El criterio de imputación temporal de dicho canon estará determinando por el momento exacto en que se produzca el uso o disfrute de dichas obras hidráulicas.

Tras lo anteriormente expuesto, debemos destacar las importantes repercusiones que entrañan las modificaciones en los instrumentos económicos de la Ley de Aguas 46/1999, en el Medio Ambiente. Y es que como bien sabemos, la reforma de la Ley de Aguas se justifica por la necesidad de acometer, mediante nuevos instrumentos más eficaces, la problemática de la gestión del agua en España y hacer frente, desde una perspectiva no sólo cuantitativa, sino también cualitativa, a las nuevas exigencias que reclama en la actualidad la administración de los recursos hídricos. Como pone de manifiesto la Exposición de Motivos de la Ley «la aplicación práctica de la Ley de Aguas de 1985 ha permitido constatar tanto la existencia de diversos problemas prácticos en la gestión del agua a nivel nacional, que deben resolverse con vistas al futuro, como la ausencia en ella de instrumentos eficaces para afrontar las nuevas demandas en relación con dicho recurso, tanto en cantidad, dado que su consumo se incrementa exponencialmente, como en calidad, teniendo en cuenta la evidente necesidad de profundizar y perfeccionar los mecanismos de protección existente en la Ley de 1985».

Por ello, «las mayores exigencias que imponen, tanto la normativa europea como la propia sensibilidad de la sociedad española» justifican la necesidad de acometer por parte de las Administraciones Públicas «la articulación de mecanismos jurídicos idóneos que garanticen el buen estado ecológico de los bienes que integran el dominio público hidráulico, a través de instrumentos diversos, como puede ser, entre otros, el establecimiento de una regulación mucho más estricta de las autorizaciones de vertido, para que éstas puedan constituir verdaderamente un instrumento eficaz en la lucha contra la contaminación de las aguas continentales, o la regulación de los caudales ecológicos como restricción general a todos los sistemas de explotación». Desde esta óptica, la reforma 
pretende incorporar a la gestión del agua una nueva perspectiva de economía del agua, a la par que fomentar una política de ahorro en los consumos y atiende de manera especial a las exigencias ambientales de protección del recurso hídrico. Si la Ley de Aguas de 1985 fue un hito en nuestro Derecho de Aguas, entre otros aspectos, debido a la incorporación de nuevos planteamientos que atendían a la consideración del valor ecológico de los recursos hídricos, las Modificaciones de la Ley de Aguas del 46/1999 profundiza en esta dimensión ecológica de las aguas continentales, otorgando mayor importancia a sus valores medioambientales.

Sin embargo, esta sensibilidad no se hace realmente patente en los diversos instrumentos económicos utilizados en la legislación; la preocupación por el medioambiente se hace visible en el artículo 84 en el que se fija como objetivos la protección del dominio público hidráulico mediante: 1) la prevención del deterioro del estado ecológico y contaminación de las aguas; 2) en establecer un programa de control de la calidad de las aguas en las cuencas hidrográficas; 3 ) impedir la acumulación de compuestos tóxicos en el subsuelo; 4) Recuperar los sistemas acuáticos. De igual modo, el artículo 90 de la Ley de Aguas expone que los Organismos de Cuenca, en las concesiones y autorizaciones que otorguen "adoptarán las medidas necesarias para hacerlas compatible el aprovechamiento con respecto al medio ambiente y garantizar los caudales ecológicos o demandas ambientales previstas en la planificación".

Y, por último, en la susodicha Ley de Aguas se realizan modificaciones en materia medioambiental respecto a los vertidos y la reutilización de las aguas depuradas; y al papel que tendrán las distintas Administraciones en la regulación y actuación en dichas materias. Pero no se establecen, realmente, medidas económicas en todos los principios establecidos, para su puesta en marcha. De hecho, solo tendríamos que hacer distinción ${ }^{3}$ entre las distintas medidas de protección ambiental, tanto prohibitivas, preventivas -autorizaciones y concesiones-, estimulantes -subvenciones y exenciones-, disuasorias -inspección y expropiación-, compensatorias -indemnizaciones- y represivas -sanciones- (sino que se centra, casi en exclusividad en las preventivas y las represivas), para darnos cuenta de que no es una Ley completa en términos económicos y no se han hecho todas las modificaciones necesarias en el texto que nos acomete (Ley de Aguas 46/1999), para que lo sea.

Así pues, podemos afirmar que, tan solo el artículo 41 de la Ley de Aguas 46/1999, se ajusta a la protección y conservación del Medio Ambiente intentando controlar y gestionar los procesos contaminadores del régimen de vertidos, aunque podríamos atribuir dicho carácter proteccionista que no preventivo, al artículo 40 de la Ley de Aguas 46/1999 por su carácter parafiscal, si bien esto no termina de justificar que se destine a la propia conservación del medioambiente. Lo que si queda claro es que la cuantificación de los hechos imponibles recogidos en los mecanismos económicos no son los suficientemente cuantiosos como para lograr, a medio plazo, la práctica erradicación del mal uso del recurso hídrico. Detengámonos en el Texto Refundido de la Ley del 2001.

3 Lozano Cuntada, B. y Alli Turrillas, J.C. (2008). Administración y Legislación Ambiental. Manual y Materiales Complementarios. Ediasa. 


\section{III.2. Actualización y cambios de los Instrumentos Económicos Texto refundido de la Ley de Aguas 1/2001}

La modificación de la Ley de Aguas 46/1999 supuso un cambio importante en la legislación de los instrumentos económicos y financieros del recurso hídrico en nuestro país, cuyo fin emanaba del interés constitucional de «velar por la utilización racional de todos los recursos naturales, con el fin de proteger y mejorar la calidad de la vida y defender y restaurar el medio ambiente, apoyándose en la indispensable solidaridad colectiva» (art. 45.2 CE). Por ello debemos destacar que en el Real Decreto Legislativo 1/2001, de 20 de julio que aprueba el texto refundido por la Ley de Aguas, se establecen los mismos instrumentos que en la modificación de la Ley de Aguas 46/1985, exceptuando algunas pequeñas cuestiones entre las que cabe destacar las recogidas en el artículo 115 (ya que en los artículos 113 y 114 no se aprecia modificación alguna, salvo que se incluyen los cambios de moneda de pesetas a euros y en el artículo 113.6. ya no se cita al artículo 96 sino al artículo 100 de la presente Ley).

Cabe destacar del Título VI del régimen económico-financiero de la utilización del dominio público hidráulico, la "Naturaleza económica y Administrativa de las liquidaciones" (art. 115 Texto refundido de la Ley de aguas, Real Decreto Legislativo 1/2001), que modifica el artículo 107 de la Ley 29/1985. Si bien, no se trata de un instrumento económico, si regula el funcionamiento y la aplicación de los mismos, recogidos en los artículos del Título VI (cuadro 7).

1. Reglamentariamente podrá establecerse la autoliquidación de los cánones o exacciones mencionados en los artículos anteriores.

2. Los actos de aprobación y liquidación de estos cánones o exacciones tendrán carácter económico-administrativo. Sin perjuicio de lo dispuesto en las normas reguladoras de los procedimientos aplicables, la impugnación de los actos no suspenderá su eficacia, siendo exigible el abono del débito por la vía administrativa de apremio. El impago podrá motivar la suspensión o pérdida del derecho a la utilización o aprovechamiento del dominio público hidráulico.

3. El pago de las exacciones previstas en la presente Ley, cuando los obligados a ello estén agrupados en una comunidad de usuarios u organización representativa de los mismos, se podrá realizar a través de tales comunidades o entidades, que quedan facultadas a tal fin para llevar a cabo la recaudación correspondiente, en los términos que se establezcan reglamentariamente.

Y es que, en el Art. 115, una de las cuestiones más relevantes, y que mayor incidencia pueda tener sobre el medio ambiente -quizás no siempre de manera positiva-, es que en el proceso de autoliquidación se permite la agilización de los cobros y el establecer facilidades para realizar el pago de dicho canon de forma conjunta por los beneficiarios del servicio, siempre y cuando 
se agrupen en una Comunidad de Usuarios u otro tipo de agrupación; esto puede llegar a potenciar la puesta en común de las necesidades vs. limitaciones de su dominio público hídrico, favoreciendo así la concienciación de todos los usuarios (aunque sea presión o coerción).

Se hace imprescindible, no obstante, señalar que las modificaciones en materia de instrumentos económicos, en la Ley de Aguas española, mediante la aprobación del Texto Refundido de la Ley de Aguas, Real Decreto 1/2001 han sido prácticamente nulas y la repercusión de estos sobre el medio ambiente es relativamente limitada. Tal afirmación se basan en la idea de que, si bien es cierto que dicho Texto Refundido de la Ley de Aguas recoge la tarificación y el pago por los daños que se puedan llegar a ocasionar en el medio ambiente, afectando de manera directa o indirecta sobre el propio recurso hídrico o sobre el resto de factores bióticos, abióticos y antrópicos que conforman un paisaje o un ecosistema contempla la prevención y la conservación del medio ambiente; cómo mucho, se hace hincapié en la posibilidad de restaurar, regenerar o recuperar aquello que ya se ha dañado, aunque no queda demasiado claro el "cómo" hacerlo. Igualmente, señalar que los tipos de gravámenes recogidos en la presente legislación difieren cuantitativamente de los propios costes y la falta de equidad que emana del propio principio de territorialidad al que se hace continuamente referencia, a la hora de delegar competencias administrativas en términos recaudatorios vs. sancionadores, con un tipo impositivo a aplicar excesivamente bajo, con lo que sale más barato causar el daño, contaminar o degradar el propio dominio público hidráulico, que prevenir y preservar el deterioro del mismo.

Por todo ello, debemos retomar la idea de que, en la fiscalidad de las aguas, y más concretamente en la Ley de Aguas española, se está utilizando de forma indiscriminada los mal denominados "canones" (como afirman numerosos expertos en la materia, entre los que destaca Ramón Falcón y Tella) que, en la mayoría de los casos, son precios públicos que conllevan una serie de vicios muy negativos. Esta exacción parafiscal se ingresa por la ocupación y aprovechamiento del bien demanial, fijándose en atención al valor de mercado o de la utilidad privada que se haya obtenido, por ello, al tratarse de un bien colectivo (tanto las obras hidráulicas como el propio abastecimiento del recurso hídrico), resulta que la contribución que se realice, sostiene el gasto público global.

Respecto de las propuestas de actuación, podemos afirmar que, una tendencia interesante dentro de este sector del agua, es la reorientación de estas clásicas figuras tributarias, eminentemente recaudatorias, y parcialmente representativas de la aplicación del principio "contaminador-pagador", hacia otras figuras más preventivas aplicadas sobre la utilización del medio ambiente, tomando en consideración el principio de "quien usa los recursos, paga". En esta línea, precisamente, puede resultar interesante la posibilidad de cambiar los tradicionales cánones de vertido por un canon amplio sobre el uso del dominio público hidráulico, de tal manera que, en lugar de insistir en gravar la capacidad de contaminante del agua residual, se trataría de gravar, el agua consumida que finalmente se convierte en un residuo contaminado. Con esta orientación se apunta hacia una optimización del agua como recurso escaso, introduciendo el factor precio para racionalizar la gestión a lo largo de todo su ciclo de uso; así pues, se podría plantear un nuevo canon de protección del dominio público, que ampliara notablemente el existente, y sustituyera al vigente canon de vertidos que, por determinadas circunstancias, se ha mostrado insuficiente, tanto por su escasa capacidad recaudatoria, como por su débil operatividad. 
Una nueva legislación del recurso hídrico en el que el régimen económico-financiero del agua se encuadre en la propia Directiva Marco del Agua y, por lo tanto, esté referenciada por las propias Cuencas Hidrográficas, pero con ciertas modificaciones, puesto que las características intrínsecas de las Cuencas Hidrográficas pueden ser empleadas o utilizadas para estudiar las condiciones generales del territorio español y, extrapolando a toda España, se puede establecer una cuantificación (una base imponible) que resulte óptima en términos recaudatorios y en términos medioambientales (protección, prevención y conservación). Para ello, se hace imprescindible generar no sólo una nueva política, sino sentar sus bases mediante un conjunto de planes, programas y proyectos que permitan, no sólo recaudar sino que también evaluar y gestionar el consumo (abastecimiento, depuración, extracción...) de agua, para poder realizar una planificación integral óptima, equitativa, eficiente y, sobre todo, sostenible (económica, ecológica y social), y en las que juegan un papel fundamental la evaluación ambiental estratégica (hoy bastante olvidada).

Con todo lo expuesto, la propuesta de unificación de la tarifa del recurso hídrico en España estaría marcada por las siguientes condiciones: en primer lugar, que se configure una nueva Política del Agua a nivel Nacional, en la que la estipulación del canon general de la exacción tributaria del recurso hídrico la establezca el propio Estado, y sea igual para todas las regiones de España, independientemente, de cuál sea su clima, hidrografía, litología, edafología, geomorfología... En segundo lugar, que las competencias recaudatorias recaigan sobre las Provincias, en lugar de las Comunidades Autónomas, puesto que resulta más sencilla la exacción de un territorio más o menos pequeño y homogéneo (aunque la descentralización puede acarrear diversas complicaciones, en este caso podría dejarse en manos de las Provincias la competencia de recaudar la tributación por el consumo de agua, y que ésta, a su vez, fuera controlada por las Comunidades Autónomas, para evitar la corrupción del sistema). Por último, el fin de la recaudación no sólo será la recuperación de costes (como estipula el art. 9 de la Directiva Marco del Agua) sino que irá destinado a la propia protección del medioambiente (y, por ende, de los ecosistemas), la recuperación de costes, la eficiencia y la equidad recaudatoria y, algo fundamental, evitar el despilfarro del agua en algunas regiones, mientras otras sufren las penumbras de la escasez, con lo que, lo recaudado servirá para financiar la creación de nuevas infraestructuras (así como procesos de control de la obtención de agua de manera privativa, irregular e ilegal) en las zonas del norte peninsular y, a su vez, generar sistemas de transporte de agua hacia las zonas del sur de España.

\section{A MODO DE CONCLUSIÓN}

Tras lo anteriormente expuesto señalar que la experiencia española en términos de legislación del recurso hídrico es especialmente interesante en este sentido, porque sus tres niveles de gobierno, el central, el regional y el local, tienen competencias en materia de fiscalidad ambiental sobre el agua. De hecho, hay un considerable número de tributos que recaen sobre el agua, la recaudación que proporcionan no es suficiente para hacer frente a los gastos e inversiones asociadas a dicho recurso (Macadán, M., 2009). La compleja delimitación competencial muestra que el Estado es competente para declarar de dominio público las aguas, y marcar su régimen competencial (se encuentren donde se encuentren), puede regular y otorgar las concesiones de las cuencas intercomunitarias, siendo compeptente para aprobar 
los planes de cuenca inter e intracomunitarios. Por su parte las Comunidades Autónomas, de acuerdo con sus Estatutos pueden regular los aprovechamientos de aguas intracomunitarias, otorgando las correspondientes concesiones, con sujeción a la legislación básica estatal. Las controversias surgidas hacen que no pocos autores (v.gr.: Embid,...) afirmen que el signo distintivo del derecho y de la política española de aguas sea su indefinición, por lo que a pesar de haber pasado ya treinta años desde su promulgación, los instrumentos y mecanismos económicos recogidos en la Ley de Aguas de 1985, coadyuvan a alcanzar un cierto orden territorial en esta materia, a nivel estatal (o podemos olvidarnos que se ve agravado por ideas como las de Martín-Retortillo Baquer según el cual, adolecemos de una política hidráulica sostenible y coherente, consecuencia de la tendencia dominante, según la cual, se tiende a marginar y romper todo lo que pueda responder a una idea de generalidad, de unión, en definitiva, de unidad).

Y es que, como hemos podido ver a lo largo de la presente exposición, las medidas puestas en marcha por las distintas administraciones han ido orientas tradicionalmente, a políticas de oferta basadas en la construcción de grandes obras de ingeniería hidráulica, con el fin principal de almacenar y distribuir el agua entre la población. Cuanto a esto, desde la instauración de la Ley de Aguas 29/1985 (y la aplicación de diversos instrumentos económicos como los canones), se dio gran importancia a la aplicación de nuevas políticas del agua, fundamentadas en la demanda, con el propósito de controlar el consumo y el mal uso del recurso hídrico (claro ejemplo de ello, lo encontramos en los canones de concesión de uso, de vertidos y en la regulación y tarificación del uso y disfrute del recurso hídrico). Todo ello, sin olvidarnos que en España, la eficacia recaudatoria de las exacciones estipuladas en la Ley de Aguas 29/1985 es muy baja, como consecuencia directa del régimen económicofinanciero y por la escasa efectividad del sistema de cobro en línea con lo que afirma el Libro Blanco del Agua (1998); «todo ello impide, en primer lugar, la recuperación de los recursos financieros necesarios para una adecuada vigilancia, control, administración, mantenimiento de las infraestructuras hidráulicas y protección del dominio público hidráulico. En segundo lugar, muestra la escasa internalización de los costes generados en el proceso por parte de los usuarios»

Por ello, la reforma de la Ley de Aguas se justifica por la necesidad de acometer, mediante nuevos instrumentos más eficaces, la problemática de la gestión del agua en España y hacer frente, desde una perspectiva no sólo cuantitativa, sino también cualitativa, a las nuevas exigencias que reclama en la actualidad la administración de los recursos hídricos. De igual modo, deberíamos incorporar a la gestión del agua una nueva perspectiva de economía del agua, a la par que fomentar una política de ahorro en los consumos y respondiendo a las exigencias ambientales de protección del recurso hídrico. Si la Ley de Aguas de 1985 fue un hito en nuestro "Derecho de Aguas", entre otros aspectos, debido a la incorporación de nuevos planteamientos que atendían a la consideración del valor ecológico de los recursos hídricos, las "Modificaciones" de la Ley de Aguas del 46/1999 profundiza en esta dimensión ecológica de las aguas continentales, otorgando mayor importancia a sus valores medioambientales. Si bien, tendríamos que hacer distinción entre las distintas medidas de protección ambiental, para darnos cuenta de que no es una Ley completa en términos económicos y no se han realizado todas las modificaciones necesarias en el texto que nos acomete (Ley de Aguas 46/1999) para que lo sea. 
Igualmente, señalar que, tan solo el artículo 41 de la Ley de Aguas 46/1999, se ajusta a la protección y conservación del Medio Ambiente intentando controlar y gestionar los procesos contaminadores del régimen de vertidos. Si bien, también podríamos atribuir dicho carácter proteccionista que no preventivo, al artículo 40 de la Ley de Aguas 46/1999 por su carácter parafiscal, aunque esto no termina de justificar que se destine a la propia conservación del medioambiente. Lo que si queda claro es que la cuantificación de los hechos imponibles recogidos en los instrumentos económicos no son los suficientemente cuantiosos como para lograr, a medio plazo, la práctica erradicación del mal uso del recurso hídrico. Y es que en España, tal y como señala el profesor Joaquín J. Marco (2009) el agua reúne disfuncionalidades típicas de una economía centralizada, pues los consumidores no tienen apenas incentivos para el ahorro; tampoco los distribuidores, pues casi siemp0re es más cara la reparación de una conducción que lo que vale (a precio de consumidor) el recurso perdido; la máxima de "quien usa los recursos, paga" debe ser la que permita vincular las medidas culturales y las económicas.

Por último, tal y como hemos señalado, se haría imprescindible elaborar una nueva Ley de Aguas, que fijase sus bases en la protección, conservación y reparación de los recursos hídricos de dominio público, donde se piense globalmente y se actúe localmente. Fundamentada y estructurada en la problemática hídrica real de nuestro país; en la que el uso racional y la protección del agua sea el eje fundamental de actuación y que, de igual modo, tenga en cuenta en su desarrollo lo ya estipulado en la Ley de Aguas 29/1985 y la modificación de sus instrumentos económicos, no tanto en pro de la recaudación como de la conservación. Los mecanismos e instrumentos económicos de la Ley de Aguas vigente cubre como puede los problemas de carácter competencial-territorial, como señala el parafraseado profesor Marco, generados por una excesiva atomización competencial asumida por diversos Ministerios, varias Consejerías de las Comunidades Autónomas, las Diputaciones, los Ayuntamientos, las Asociaciones de Regantes,..., lo que lleva a la descoordinación y a la ineficacia, impidiendo alcanzar un verdadero desarrollo sostenible (tanto territorial como económica y socialmente).

\section{AGRADECIMIENTOS}

La presente investigación se enmarca en el Proyecto del MINECO (2014).CTM201341750-P, del Ministerio de Economía, Industria y Competitividad de España. Igualmente, señalar que el tercero de los autores disfruta, en los momentos actuales, de un contratado F.P.U. (Formación del Profesorado Universitario), del Ministerio de Educación, Cultura y Deporte.

\section{BIBLIOGRAFÍA}

ALBI, E. et ali (2008): Economía Pública I. Ariel. Madrid.

ARGULLOL MURGADAS, E. y GUTIERREZ MUÑO YERRO, J. (1992): El régimen económico-financiero en el Plan Hidrológico Nacional. Política hidráulica.

ARRIETA MARTÍNEZ DE PISÓN, J. (1991): Régimen discal de las aguas. Cuadernos Cívitas.

CABEZAS CALVO-RUBIO, F. et ali (2010): Agua y Estatutos de Autonomía: El caso castellano-manchego. Asociación Valenciana de Empresarios. 
CASTRO RIBERA, De J.F. (1997): La economía del agua: la viabilidad de un mercado. Documento de trabajo, La Laguna.

CHICO DE LA CÁMARA, P. (1998): El uso de contribuciones especiales para financiar la ejecución de obras hidráulicas medioambientales. Noticias de la Unión Europea.

CHICO DE LA CÁMARA, P. (1998): Análisis comparativo en el sistema italiano y español del uso de constribuciones especiales para financiar la ejecución de obras hidráulicas medioambientales. En Fiscalidad Ambiental. Cedecs Derecho Financiero y Tributario.

EMBID IRUJO, A. (2002): «Evolución del Derecho y de la Política del Agua en España», en Embid Irujo, A. Director (2002): El Derecho de Aguas en Iberoamérica y en España: Cambio y modernización en el inicio del Tercer Milenio. Tomo 1. Civitas, Madrid.

EMBID IRUJO, A. (2007): Conflictos jurídicos en la gestión y uso del agua. Consejo General del Poder Judicial, Madrid.

EMBID IRUJO, A. (Dir.) (2007): Diccionario de derecho de aguas. Iustel.

EMBID IRUJO, A. (2010): La política de aguas y su marco jurídico. Fundación Nueva Cultura del Agua. Sevilla.

EMBID IRUJO, A. Director (2016): Treinta años de la Ley de Aguas de 1985. Editorial Thomson Reuters Aranzadi.

FALCÓN Y TELLA, R. (1991): «Aproximación al contenido del tributo como instituto jurídico», en Estudios Jurídicos en conmemoración del X Aniversario de la Facultad de Derecho de la Universidad de Córdoba, Córdoba.

GAGO, A. y LABANDERÍA, X. (1999): La reforma fiscal verde: teoría y práctica de los impuestos ambientales, Madrid, Mundiprensa.

GARCÍA BALLESTEROS, A. (2000): «La cuestión ambiental en la Geografía del siglo XX». Anales de Geografía de la Universidad Complutense de Madrid, $\mathrm{n}^{\circ}$ 20, pp. 101114.

JIMÉNEZ HERRERO, L. (1998): «Tendencias en el uso de instrumentos económicos y fiscales en la gestión ambiental. Reflexiones sobre la Unión Europea y el caso español». En Fiscalidad Ambiental. Cedecs Derecho Financiero y Tributario.

LEY DE AGUAS ESPAÑOLA, 29/1985, de 2 de agosto.

LA-ROCA, F. (2008): El desarrollo de la Directiva Marco del Agua y los nuevos instrumentos económicos en la gestión del agua. Fundación Nueva Cultura del Agua. Convenio Universidad de Sevilla y Ministerio de Medio Ambiente. Sevilla.

LLAMAS, R. (1998): «Comentario a la propuesta de reforma de la Ley de Aguas de 1985», en Diario de Sesiones del Congreso de los Diputados $n^{\circ} 4460$.

LOZANO CUNTADA, B. y ALLI TURRILLAS, J.C. (2008): Administración y Legislación Ambiental. Manual y Materiales Complementarios. Ediasa.

MAGADÁN, M. (2009): «Distribución territorial de la tributación ambiental y el consumo de agua», Castilla La Mancha., Clm. Economía, no 15. pp. 271-326.

MARTÍN-RETORTILLO BAQUER, S. (2000): Las obras hidráulicas en la Ley de Aguas. Madrid., Cuadernos Civitas, p. 42.

MARTÍNEZ, J. y ROCA, J. (2016): Economía ecológica y política ambiental. Ciudad de México, Editorial F.C.E. $3^{\text {a }}$ edición, $1^{\text {a }}$ reimpresión.

MARTÍNEZ GIL, F.J. (1997): La nueva cultura del agua en España. Bilbao, BAKEAZ. 
MÉNDEZ, A. (2016): «La génesis de la Ley de Aguas de 1985: Problemas y objetivos». En Embid, A. (Director). «Treinta años de la Ley de Aguas de 1985., Zaragoza., Thomson Reuters Aranzadi.

MINISTERIO DE MEDIO AMBIENTE (1998): Libro Blanco del Agua en España. Documento de síntesis. Madrid.

MODIFICACIONES DE LA LEY DE AGUAS ESPAÑOLA, 46/1999, de 14 de diciembre.

MOPTMA (1994): Economía y racionalización de los usos del agua. Seminario de la Universidad Internacional Menéndez Pelayo de Santander. Centro de Publicaciones, Secretaría General Técnica, Madrid.

NAREDO, J.M (1997): La economía del agua en España. Fundación Argentaria-Visor Distribuciones, Madrid.

NAREDO, J.M (2008): “Costes y cuentas del agua. Propuestas desde el enfoque integrador”. Seminario Costes y cuentas del agua en Cataluña, en relación con la Directiva Marco del Agua. Agencia Catalana del Agua.

PAGÉS I GALTÉS, J. (1995): Fiscalidad de las aguas. Marcial Pons.

PAGÉS I GALTÉS, J. (2011): Fiscalidad de las aguas. Fundación Democracia y Gobierno Local.

PÉREZ DÍAZ, V., MEZO, J., ÁLVAREZ-MIRANDA, B. (1996): Política económica del agua en España. Círculo de empresarios, Madrid.

PIGOU, A. (1920): The Economics of Welfare. Macmillan, Londres.

PROGRAMA A.G.U.A. http://www.mma.es/secciones/agua/entrada.htm

PORTA, F. (2001): La Directiva Marco del Agua: aplicación del principio de recuperación de los costes en el sector urbano del agua en España, en La DMA y sus implicaciones para la gestión del agua en España». CENTA. Sevilla.

REGLAMENTO DEL DOMINIO PÚBLICO HIDRÁULICO, REAL DECRETO 849/1986, de 11 de abril.

RICO GONZÁLEZ, M. y GÓMEZ-LIMÓN RODRÍGUEZ, J.A. (2005): «Los mercados del agua: análisis de los condicionantes para su correcto desarrollo en España». Estudios Agrosociales y Pesqueros, n 206, pp. 33-62.

ROSEMBUJ, T. (1995): Los tributos y la protección del medio ambiente. Marcial Pons.

SERRANO ANTÓN, F. (2010). Las tasas por la prestación de servicios y realización de actividades administrativas en la Hacienda Local. Anuario Aragonés del Gobierno Local.

SOTELO NAVALPOTRO, J.A., SOTELO PÉREZ, M. y SOTELO PÉREZ, I. (2015): «Territorio y sostenibilidad: Algunos problemas medioambientales en España (I)». $M+A$ Revista Electrónica de Medioambiente, vol. 16, nº1, pp. 45-79.

SOTELO NAVALPOTRO, J.A. (2012): «Cambio climático, riesgos naturales y tecnológicos en el contexto de los modelos de desarrollo». Observatorio Medioambiental, $\mathrm{n}^{\circ}$ 15, pp. 239-272.

SOTELO NAVALPOTRO, J.A. (2008): «Riesgos naturales y tecnológicos en España, hoy». Observatorio Medioambiental, $\mathrm{n}^{\mathrm{o}}$ 15, pp. 9-12.

SOTElO NAVAlpotro, J.A. (2007): Medio Ambiente, Desarrollo y Sostenibilidad. Modelos y Políticas de actuación contradictorias: entre lo global y lo local. Oxford University Press, pp. 428. 
SOTELO NAVALPOTRO, J.A. (2006): «Intersecciones entre los modelos territoriales y los modelos de desarrollo en el ámbito del medio ambiente». Observatorio Medioambiental, $\mathrm{n}^{\circ} 10, \mathrm{pp} .79-119$.

SOTELO NAVALPOTRO, J.A. (2006): «Desarrollo y medioambiente en el municipio de Madrid: Abastecimiento y saneamiento urbano». Observatorio Medioambiental, $\mathrm{n}^{\circ}$ 9, pp. 215-264.

SOTELO NAVALPOTRO, J.A. (2006): «Bases territoriales de la planificación integral. El estudio de caso: La Cuenca del Tajo. Madrid». Revista de Arte, Geografía e Historia, ${ }^{\circ}$ 8. pp. 359- 96.

SOTELO NAVALPOTRO, J.A. (2001): Estudiar la Región. Infodal, pp.285.

SOTELO NAVALPOTRO, J.A. (2001): «Environmental Europe». Oxford University Press, pp. 195

SOTELO PÉREZ, M. y SOTELO PÉREZ, I. (2014): «Planificación y gestión del agua en España, en la actualidad». Observatorio Medioambiental, nº 17, pp. 375-408.

SUMMER, L. H. (1991): "The case for corrective taxation, National». Tax Journal, 44, pp. 289-292.

TAMAMES, R. y AURÍN, R. (2015): Gobernanza y gestión del agua: Modelos público y privado. Barcelona, editorial PROFIT.

TEXTO REFUNDIDO DE LA LEY DE AGUAS, REAL DECRETO LEY 10/2001, de 20 de julio.

TEXTO REFUNDIDO DE LA LEY DE HACIENDAS LOCALES, REAL DECRETO 2/2004, de 5 de marzo

TEXTO REFUNDIDO DE LA LEY DE CONTRATOS DEL SECTOR PÚBLICO, REAL DECRETO LEGISLATIVO 3/2011.

VÁZQUEZ, C. (2004): «La fiscalidad de las aguas en España». En Tributación medioambiental: Teoría, práctica y propuestas». Civitas. Madrid, 147-184.

ZÁRATE, A. et alii (2007): «Descentralización fiscal y tributación ambiental». En XXIII Reunión de Estudios Regionales. Castilla y León. 